\title{
Fluorescence of thulium-doped translucent zirconia
}

\author{
Takashi NAKAMURA ${ }^{1}$, Shinya OKAMURA ${ }^{1}$, Hisataka NISHIDA², Hirofumi USAMI ${ }^{1}$, Yoshiro NAKANO'1, \\ Kazumichi WAKABAYASHI ${ }^{1}$, Tohru SEKINO ${ }^{2}$ and Hirofumi YATANI ${ }^{1}$ \\ ${ }^{1}$ Department of Fixed Prosthodontics, Osaka University Graduate School of Dentistry, 1-8 Yamadaoka, Suita, Osaka 565-0871, Japan \\ ${ }^{2}$ Institute of Scientific and Industrial Research, Osaka University, 8-1 Mihogaoka, Ibaraki, Osaka 567-0047, Japan \\ Corresponding author, Takashi NAKAMURA; E-mail: tnakamur@dent.osaka-u.ac.jp
}

\begin{abstract}
The fluorescence and physical properties of thulium-doped zirconia were investigated. A standard grade of zirconia (TZ-3Y-E) and two translucent dental zirconia materials (Zpex and Zpex Smile) were examined. The specimens were prepared by addition of 0-1.5 wt\% $\mathrm{Tm}_{2} \mathrm{O}_{3}$ and then sintering. When exposed to UV light, the $\mathrm{Tm}_{2} \mathrm{O}_{3}$-doped zirconia exhibited blue fluorescence with a peak wavelength of $460 \mathrm{~nm}$. The fluorescence intensity of Zpex and Zpex Smile was higher than that of TZ-3Y-E, with Zpex being more intense than Zpex Smile. Zpex exhibited maximum fluorescence intensity when doped with $0.8 \mathrm{wt} \% \mathrm{Tm}_{2} \mathrm{O}_{3}$. XRD analysis revealed that TZ-3Y-E and Zpex contained primarily tetragonal zirconia, while Zpex Smile contained largely cubic phase zirconia. There were no changes observed in the microstructure or physical properties of the zirconia specimens when doped with $\mathrm{Tm}_{2} \mathrm{O}_{3}$.
\end{abstract}

Keywords: Zirconia, Fluorescence, Thulium, Monolithic fixed dental prosthesis, CAD/CAM

\section{INTRODUCTION}

With the growing demand for esthetic dental treatments, patients want prosthetics with whiter and brighter teeth. Generally, ceramics are used for the fabrication of tooth-colored fixed dental prostheses. Zirconia has the highest resistance to fracture among dental ceramics because of its great strength and fracture toughness ${ }^{1}$. The difficulties associated with manually compensating for the shrinkage of zirconia that occurs during sintering have been overcome with the advent of CAD/CAM systems. This allows these materials to be processed with great accuracy, which has led to the popularity of zirconia in the clinical dental setting ${ }^{2,3)}$.

Zirconia has a crystalline structure that is stabilized in the tetragonal phase by the addition of yttria. This material was first used in dentistry to make the frames of fixed dental prostheses. While it was a strong material, it was not very translucent ${ }^{2,4)}$ and so these zirconia frameworks needed to be veneered with porcelain. This leads to problems with the porcelain veneer on the framework chipping or fracturing ${ }^{5-7)}$. A new form of zirconia has been developed recently ${ }^{7,8)}$ that is more translucent than the form traditionally used for frameworks. A monolithic, fixed dental prosthesis has been fabricated from this translucent zirconia, which reproduces the natural color of teeth and is highly resistant to fracture ${ }^{9,10)}$.

Natural teeth are fluorescent, which gives them a visual quality beyond the shades shown on the product shade guide ${ }^{11,12)}$. When exposed to UV light, the fluorescence of natural teeth makes them appear a bluish white and those in areas within the oral cavity that are poorly lit look whiter and brighter than non-

Color figures can be viewed in the online issue, which is available at J-STAGE.

Received Oct 30, 2017: Accepted Mar 5, 2018

doi:10.4012/dmj.2017-384 JOI JST.JSTAGE/dmj/2017-384 fluorescent materials ${ }^{13}$. Therefore, glass ceramics and resin composites that are used as tooth-colored materials often incorporate fluorescent materials ${ }^{14,15)}$.

Dental zirconia is not generally fluorescent ${ }^{16)}$ and so when it is used as a framework for prosthesis it is commonly veneered with fluorescent porcelain. However, when making a monolithic prosthesis it is preferable that the zirconia itself fluoresces. The addition of small amounts of rare-earth elements ${ }^{17}$ used in inorganic fluorescent pigments would likely make zirconia fluorescent. To examine this proposal, zirconia specimens with trace amounts of added thulium were prepared and the fluorescence, translucency and physical properties of these materials were evaluated.

\section{MATERIALS AND METHODS}

\section{Specimens}

Three commercially available yttria-stabilized zirconia powders (TZ-3Y-E, Zpex, and Zpex Smile) were used as the starting materials for the samples (Tosoh, Tokyo, Japan). TZ-3Y-E is a standard grade of zirconia and both Zpex and Zpex Smile are translucent dental zirconia materials. TZ-3Y-E contains $0.25 \mathrm{wt} \%$ alumina, while Zpex and Zpex Smile contain almost no alumina. Zpex Smile contains more yttria than the other two types of zirconia that we used (Table 1).

The specimens were prepared using the following procedure: thulium $\left(\mathrm{Tm}_{2} \mathrm{O}_{3}\right)$ powder was added at different concentrations $(0,0.5,0.8,1.0,1.2$, and 1.5 wt\%) to each of the three zirconia powders. The mixtures were subjected to wet ball-milling for $24 \mathrm{~h}$ using ethanol and zirconia balls, followed by dry ball-milling for $24 \mathrm{~h}$ using zirconia balls. After milling, the powder mixtures were molded into pellets under cold isostatic pressure (CIP) at $200 \mathrm{MPa}$ for $5 \mathrm{~min}$ and then sintered at $1,500^{\circ} \mathrm{C}$ 
Table 1 Compositions of materials

\begin{tabular}{cccc}
\hline Material (Trade name) & $\mathrm{Y}_{2} \mathrm{O}_{3}(\mathrm{wt} \%)$ & $\mathrm{Al}_{2} \mathrm{O}_{3}(\mathrm{wt} \%)$ & $\mathrm{SiO}_{2}, \mathrm{Fe}_{2} \mathrm{O}_{3}(\mathrm{wt} \%)$ \\
\hline Conventional Y-TZP (TZ-3Y-E) & 5.26 & 0.251 & $\leqq 0.002$ \\
Translucent Y-TZP (Zpex) & 5.35 & 0.048 & $\leqq 0.002$ \\
Translucent Y-TZP (Zpex Smile) & 9.42 & 0.049 & $\leqq 0.002$ \\
\hline
\end{tabular}

for $2 \mathrm{~h}$. The heating and cooling rates used for each specimen were $10^{\circ} \mathrm{C} / \mathrm{min}$. After sintering, each pellet was polished with a water resistant \#1000 abrasive paper, which yielded the final disk-shaped zirconia specimens (diameter $=12 \mathrm{~mm}$, thickness $=1.0 \mathrm{~mm}$ ). Five disks were fabricated for each of the six doping concentrations for the three different zirconia samples, giving a total of 90 specimens.

\section{Fluorescence and translucency}

The fluorescence spectra of the specimens (excitation wavelength $=365 \mathrm{~nm}$, irradiance $=743 \mu \mathrm{W} / \mathrm{cm}^{2}$ ) were recorded using a fluorescence spectrophotometer (FP6500 , JASCO, Tokyo, Japan). In addition, the intensity of the fluorescence produced at $460 \mathrm{~nm}$ was measured. The translucency of each specimen was evaluated using the translucency parameter (TP). The TP was obtained by measuring the CIE LAB coordinates placed on a standard white plate $\left(\mathrm{L}^{*}: 98.21, \mathrm{a}^{*}\right.$ : $\left.-0.29, \mathrm{~b}^{*}: 4.41\right)$ and a black plate $\left(\mathrm{L}^{*}: 7.39, \mathrm{a}^{*}\right.$ : $\left.-0.13, \mathrm{~b}^{*}: 2.55\right)$ using a spectrophotometer (CM-2600d, Konica Minolta, Tokyo, Japan). The measurements were repeated three times and the average values were calculated. After measurement, the TPs of each specimen were determined by the color difference on black (B) and white (W) backgrounds using the following formula:

$$
\mathrm{TP}=\left[\left(\mathrm{L}_{\mathrm{B}} *-\mathrm{L}_{\mathrm{W}}{ }^{*}\right)^{2}+\left(\mathrm{a}_{\mathrm{B}} *-\mathrm{a}_{\mathrm{W}}{ }^{*}\right)^{2}+\left(\mathrm{b}_{\mathrm{B}} *-\mathrm{b}_{\mathrm{W}} *\right)^{2}\right]^{1 / 2}
$$

\section{Crystalline structure and physical properties}

The crystalline structures of the $\mathrm{Tm}_{2} \mathrm{O}_{3}$-free and $\mathrm{Tm}_{2} \mathrm{O}_{3}$ doped specimens were analyzed using X-ray diffraction (XRD; D8 Advance, Bruker AXS, Karlsruhe, Germany). The specimens were polished to a mirror finish (\#10000 grit) using a diamond lapping film (3M Japan, Tokyo, Japan) and then some of the specimens thermally etched at $1,400^{\circ} \mathrm{C}$ for 30 min in the ambient atmosphere. The microstructure of the thermally etched specimens was observed using a scanning electron microscope (SEM; SU9000; Hitachi High-Technologies, Tokyo, Japan). Furthermore, the hardness of each specimen was measured in accordance with JIS R 160718) using a Vickers hardness meter (FV-310e, FUTURE-TECH, Kawasaki, Japan) by applying a 98 N (10 Kgf) load to each specimen for $20 \mathrm{~s}$ using a diamond indenter. The fracture toughness was measured using the indentation fracture (IF) method by examining the indentation created by the Vickers indenter and any cracks that occurred in the specimen. The fracture toughness (K1c) of each specimen was calculated using the following formula ${ }^{19)}$ :
$\mathrm{K} 1 \mathrm{c}=0.018(\mathrm{E} / \mathrm{H})^{0.5}\left(\mathrm{P} / \mathrm{c}^{1.5}\right)$,

where $\mathrm{E}$ is the elastic modulus in $\mathrm{GPa}, \mathrm{H}$ is the Vickers hardness $(\mathrm{HV}), \mathrm{P}$ is the indentation load in $\mathrm{N}$, and $\mathrm{c}$ is half of the crack length in $\mathrm{m}$.

A statistical comparison of the fluorescence intensities, TP values, Vickers hardness and fracture toughness of the specimens was performed using oneway ANOVA and Tukey-Kramer's multiple comparisons test. SPSS Statistics 17.0 (IBM Japan, Tokyo, Japan) statistical software program was used for the statistical analysis. The level of significance was set at $5 \%$.

\section{RESULTS}

\section{Fluorescence and translucency}

When exposed to UV light, the $\mathrm{Tm}_{2} \mathrm{O}_{3}$-free specimens did not fluoresce at all while those doped with $\operatorname{Tm}_{2} \mathrm{O}_{3}$ emitted a blue fluorescence (Fig.1). The fluorescence of the Zpex and Zpex Smile specimens that were doped with $\mathrm{Tm}_{2} \mathrm{O}_{3}$ was more intense than that of the TZ-3Y-E specimens doped with $\mathrm{Tm}_{2} \mathrm{O}_{3}$.

The fluorescence spectra of the specimens containing $0.8 \mathrm{wt} \% \mathrm{Tm}_{2} \mathrm{O}_{3}$ are shown in Fig. 2. These samples emitted a blue fluorescence with a peak wavelength of $460 \mathrm{~nm}$ when exposed UV light (365 $\mathrm{nm}$ ). The intensity of the fluorescence produced by the translucent Zpex samples with different doping concentrations was 1.8 to 2.7 times greater than that observed from the TZ-3Y-E samples, while that from the Zpex Smile samples was 1.4 to 2.1 times greater than the TZ-3Y-E samples (Fig. 3).

All three zirconia specimens that were free of $\mathrm{Tm}_{2} \mathrm{O}_{3}$ did not exhibit any significant fluorescence. The Zpex specimens that were doped with $\mathrm{Tm}_{2} \mathrm{O}_{3}$ exhibited the highest fluorescence intensity, followed by the Zpex Smile specimens and then the TZ-3Y-E specimens, regardless of the amount of $\mathrm{Tm}_{2} \mathrm{O}_{3}$ added. The Zpex and Zpex Smile specimens that were doped with $0.8 \mathrm{wt} \%$ of $\mathrm{Tm}_{2} \mathrm{O}_{3}$ exhibited the most intense fluoresce and the fluorescence intensity of all three zirconia specimens decreased when doped with $1.5 \mathrm{wt} \% \mathrm{Tm}_{2} \mathrm{O}_{3}$.

TZ-3Y-E was less translucent than the other zirconia specimens, regardless of the amount of $\mathrm{Tm}_{2} \mathrm{O}_{3}$ added (Fig. 4). Zpex Smile was more translucent than Zpex at most doping concentrations examined. In addition, there was no difference in the translucency of Zpex or Zpex Smile when doped with 0.5 or $0.8 \mathrm{wt} \% \mathrm{Tm}_{2} \mathrm{O}_{3}$.

Crystalline structures and physical properties $\mathrm{XRD}$ analysis showed peaks that were characteristic 


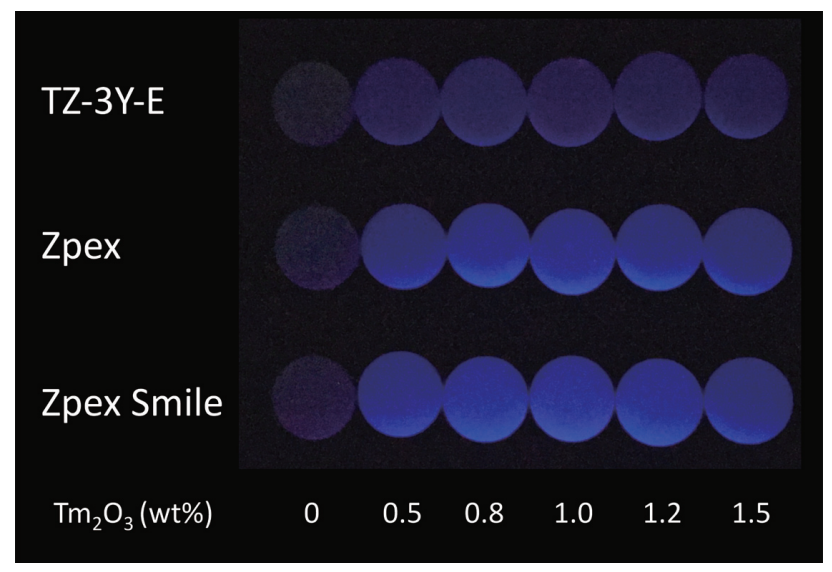

Fig. 1 Images of zirconia specimens exposed to UV light.

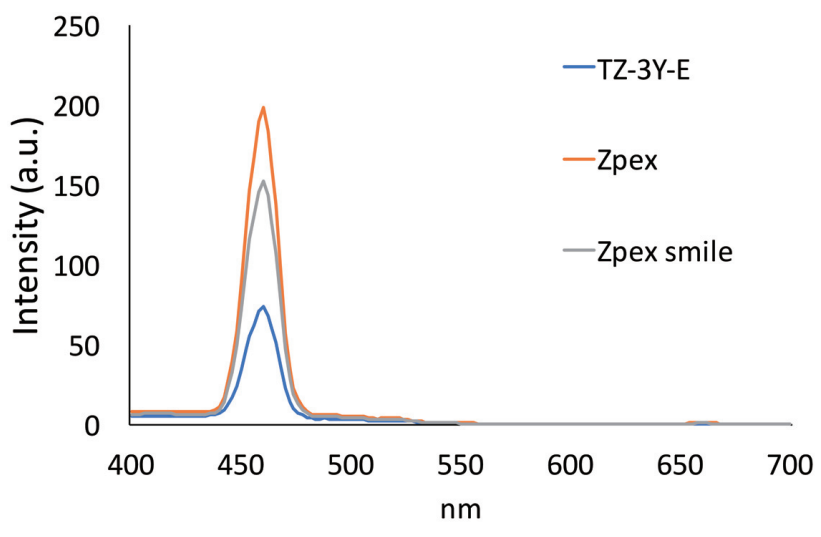

Fig. 2 Photoluminescence spectrum of 0.8 wt $\% \mathrm{Tm}_{2} \mathrm{O}_{3}$ doped zirconia specimens under UV irradiation.
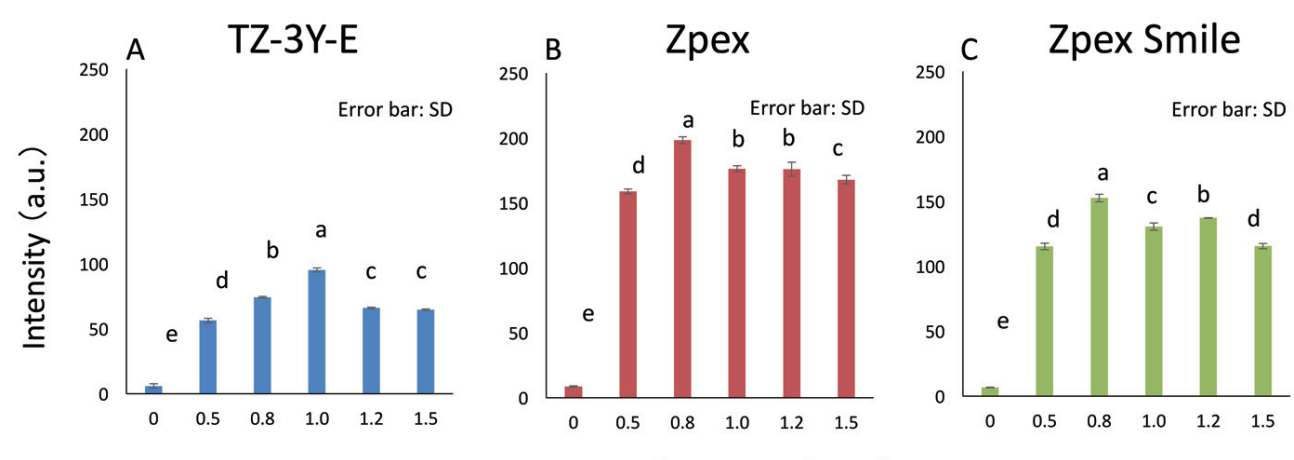

$\mathrm{Tm}_{2} \mathrm{O}_{3}$ Amount (wt\%)

Fig. 3 Relative excitation intensity of zirconia specimens at a wavelength $460 \mathrm{~nm}$ with different additive amount of $\mathrm{Tm}_{2} \mathrm{O}_{3}$ under UV irradiation.

The same superscript letters were not significantly different $(p<0.05)$.

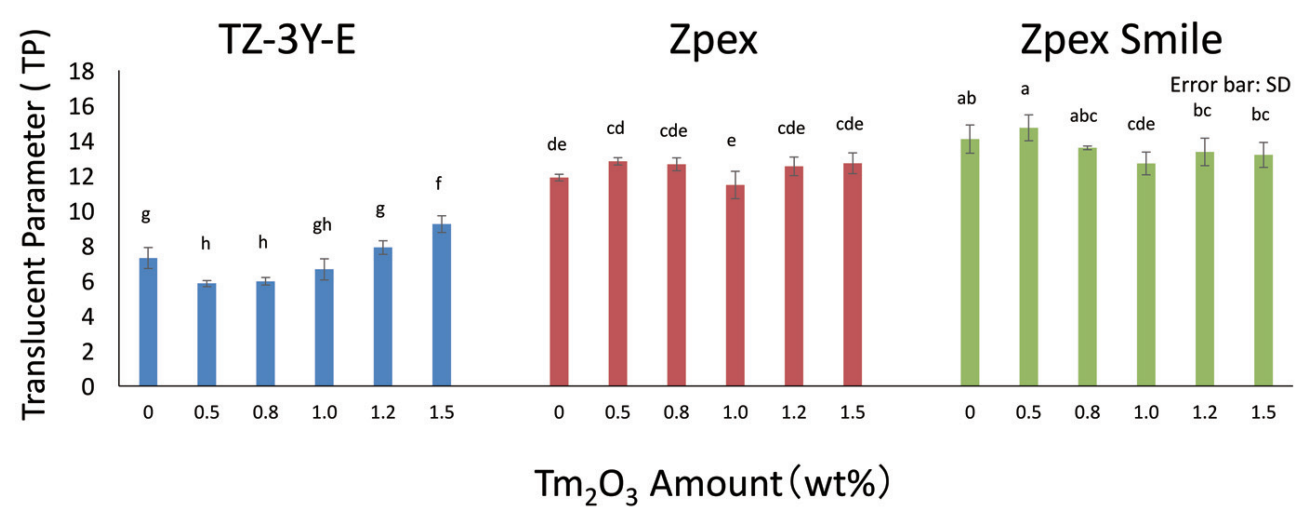

Fig. 4 Translucent parameter of zirconia specimens with different additive amount of $\mathrm{Tm}_{2} \mathrm{O}_{3}$

The same superscript letters were not significantly different $(p<0.05)$.

of the tetragonal phase for both TZ-3Y-E and Zpex, while Zpex Smile exhibited peaks characteristic of the cubic phase. For example, near $35^{\circ}$ TZ-3Y-E and Zpex exhibited two peaks at $34.6^{\circ}$ and $35.2^{\circ}$, while Zpex Smile had one peak at $35.0^{\circ}$ (Fig. 5).

SEM pictures revealed that the Zpex Smile specimens had a larger crystal grain size than the other two zirconia specimens (Fig. 6). There were no 


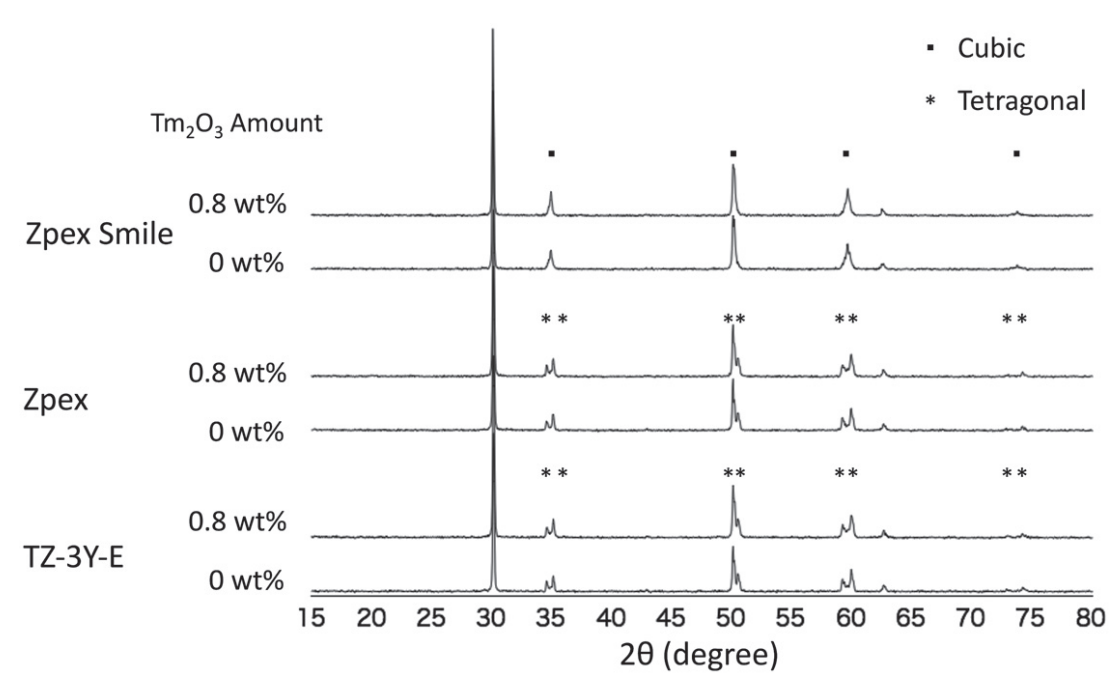

Fig. 5 XRD patterns of zirconia specimens with or without $\mathrm{Tm}_{2} \mathrm{O}_{3}(0.8 \mathrm{wt} \%)$ addition.
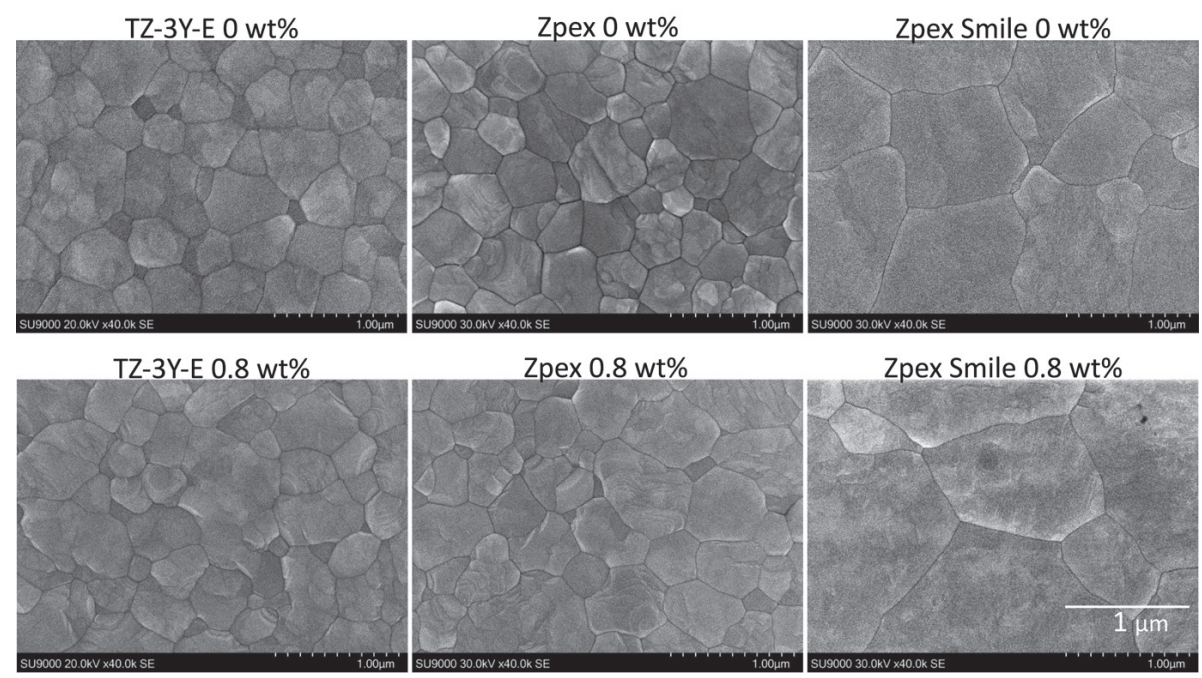

Zpex Smile 0.8 wt\%

Fig. 6 SEM images of zirconia specimens with or without $\operatorname{Tm}_{2} \mathrm{O}_{3}(0.8 \mathrm{wt} \%)$ addition.

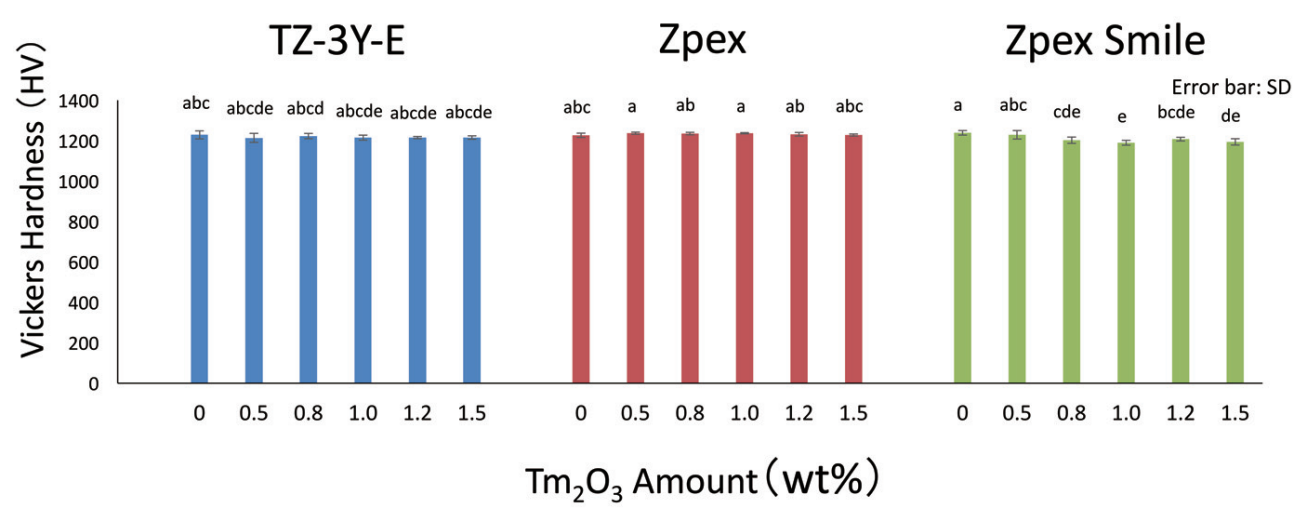

Fig. 7 Vickers hardness of zirconia specimens with different additive amount of $\mathrm{Tm}_{2} \mathrm{O}_{3}$. The same superscript letters were not significantly different $(p<0.05)$. 


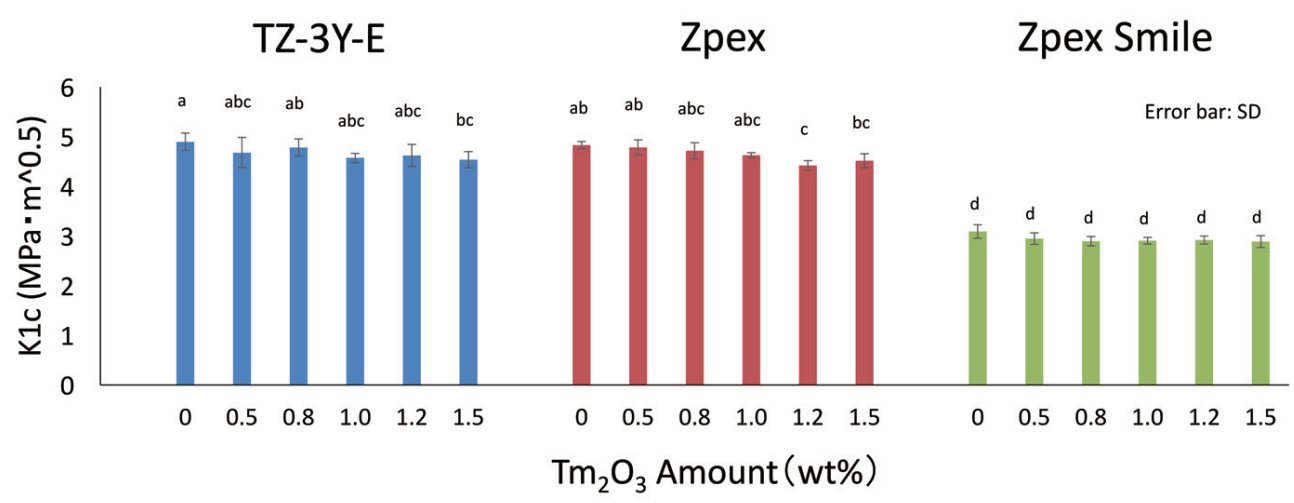

Fig. 8 Fracture toughness (K1c) of zirconia specimens with different additive amount of $\mathrm{Tm}_{2} \mathrm{O}_{3}$.

The same superscript letters were not significantly different $(p<0.05)$.

obvious differences in the crystalline structures of any of the zirconia specimens that were $\mathrm{Tm}_{2} \mathrm{O}_{3}$-free or doped with 0.8 wt $\% \mathrm{Tm}_{2} \mathrm{O}_{3}$. The three zirconia specimens had Vickers hardness values ranging from 1,194 to 1,239, and these values were almost identical at all $\mathrm{Tm}_{2} \mathrm{O}_{3}$ doping concentrations (Fig.7). The fracture toughness values (K1c) for TZ-3Y-E were 4.54-4.90, 4.42-4.84 for Zpex, and 2.89-3.10 for Zpex Smile. That is, those of Zpex Smile were lower than those of the other two zirconia specimens (Fig. 8).

\section{DISCUSSION}

Tooth-colored porcelains that are used to make fixed dental prostheses are fluorescent when rareearth elements are added to the glass matrix in trace amounts ${ }^{20,21)}$. Rare-earth elements used for this purpose include the oxides of cerium, europium, terbium, dysprosium, and samarium ${ }^{22}$.

Zirconia is a polycrystalline material that, unlike porcelain, does not have a glass matrix. However, the addition of trace amounts of a rare-earth element, such as neodymium, europium or erbium, will cause the alumina present in the material to fluoresce ${ }^{23)}$.

Zirconia nanocrystals that contain the rare earth element thulium emit blue fluorescence when exposed to UV light ${ }^{24)}$. There are reports of fluorescence from pure zirconia (monoclinic phase) that has been doped with $\mathrm{Tm}^{3+}$ ions or yttria-rich tetragonal phase-stabilized zirconia $^{25,26)}$. However, there are no reports that examine the fluorescence caused by the presence of $\mathrm{Tm}^{3+}$ ions in dental zirconia that is stabilized in the tetragonal phase by the addition of yttria. The dentin present in natural teeth emit blue fluoresence ${ }^{27)}$ when exposed to UV light $(365 \mathrm{~nm})$. Therefore, we have examined the fluorescence from dental zirconia containing various amounts of $\mathrm{Tm}_{2} \mathrm{O}_{3}$. Incidentally, euro banknotes make use of the fact that thulium $\left(\mathrm{Tm}^{3+}\right)$ fluoresces blue when exposed to UV light ${ }^{28)}$.

In preliminary experiments, we observed that the fluorescence of TZ-3Y-E specimens doped with $\mathrm{Tm}_{2} \mathrm{O}_{3}$ decreased substantially when the doping concentration was increased from $1.0 \mathrm{wt} \%$ to 3.0 or $5.0 \mathrm{wt} \%$. Therefore, the maximum amount of $\mathrm{Tm}_{2} \mathrm{O}_{3}$ added was limited to $1.5 \mathrm{wt} \%$.

Zirconia that is stabilized with the rare-earth element yttria is used to make fixed dental prostheses. The addition of yttria without a lanthanoid does not make zirconia fluoresce ${ }^{16)}$ and this is probably because lanthanoids contain electrons in their $\mathrm{f}_{\text {orbital }}{ }^{29}$ ) that are necessary for fluorescence to occur, but yttria does not.

The $\mathrm{Tm}_{2} \mathrm{O}_{3}$-free zirconia specimens did not fluoresce when exposed to UV light. However, all specimens doped with $\mathrm{Tm}_{2} \mathrm{O}_{3}$ emitted blue fluorescence, which indicated that the addition of $\operatorname{Tm}_{2} \mathrm{O}_{3}$ was an effective method to cause these materials to fluoresce. The fact that the fluorescence of Zpex and Zpex Smile was more intense than that of TZ-3Y-E was likely caused by the difference in the translucency of the materials.

A silica-on-silicon waveguide that was doped with thulium displayed blue fluorescence with peaks at 455 and $475 \mathrm{~nm}$ when exposed to UV light ${ }^{30)}$. The $\mathrm{Tm}_{2} \mathrm{O}_{3}$ doped specimens examined in this study exhibited blue fluorescence with a peak wavelength of $460 \mathrm{~nm}$, which was close to the values from the thulium-doped waveguide.

The peak fluorescent intensity varied with the amount of $\mathrm{Tm}_{2} \mathrm{O}_{3}$ that was added. The fluorescence from TZ-3Y-E was most intense when $1.0 \mathrm{wt} \%$ of $\mathrm{Tm}_{2} \mathrm{O}_{3}$ was added while that of Zpex and Zpex Smile most intense when $0.8 \mathrm{wt} \%$ of $\mathrm{Tm}_{2} \mathrm{O}_{3}$ was added. The fluorescence intensity from the three zirconia specimens did not increase any further when more $\mathrm{Tm}_{2} \mathrm{O}_{3}$ was added beyond 0.8 wt\% (Zpex and Zpex Smile) or $1.0 \mathrm{wt} \%$ (TZ3Y-E). This may have been caused by concentration quenching ${ }^{31,32)}$, which has been reported to occur in a glass that had erbium added to it.

Although Zpex Smile was slightly more translucent than Zpex, its fluorescence was less than that of Zpex regardless of how much $\mathrm{Tm}_{2} \mathrm{O}_{3}$ was added. Energy transfer in the form of UV radiation is known to affect the fluorescence of glass ${ }^{33)}$. We can assume that more UV 
energy was transferred to the yttria in the Zpex Smile as it contained higher levels of yttria than Zpex, and this may have caused the lower fluorescence intensity.

The translucency of the zirconia specimens reported previously ${ }^{34,35)}$ was higher in the monolithic translucent zirconia Zpex and Zpex Smile than in TZ-3Y-E. TZ-3Y-E contains alumina as an aid for sintering ${ }^{36}$, but the other zirconia samples do not contain any significant amounts of alumina. The refractive index of alumina (1.76) is slightly lower than that of zirconia (2.15). Therefore, the presence of alumina appears to increase light scattering ${ }^{35,37)}$, which resulted in TZ-3Y-E being less translucent than Zpex and Zpex Smile. In addition, none of the zirconia specimens exhibited a reduction in their TPs when $\mathrm{Tm}_{2} \mathrm{O}_{3}$ was added to them, which showed that the addition of $\mathrm{Tm}_{2} \mathrm{O}_{3}$ in concentrations from 0.5 to 1.5 wt\% did not affect the translucency of the zirconia.

Our XRD analysis showed that TZ-3Y-E and Zpex consisted mainly of tetragonal phase zirconia, while the Zpex Smile consisted primarily of cubic phase zirconia. These results were consistent with the literature ${ }^{35}$. SEM revealed that the Zpex Smile contained larger crystals than the other two types of zirconia powder and that they appeared to be largely cubic phase zirconia. Again, these results were consistent with the literature ${ }^{10,35)}$.

It is likely that Zpex Smile was more translucent than Zpex because of reduced light scattering at the grain boundaries, as it contains more of the optically isotropic cubic zirconia ${ }^{38)}$. The addition of $\mathrm{Tm}_{2} \mathrm{O}_{3}$ to the zirconia did not change the XRD results, which indicated that the presence of $\operatorname{Tm}_{2} \mathrm{O}_{3}$ did not affect the crystalline structure of the zirconia within the doping concentration range examined in this study.

Highly translucent dental zirconia, which contains a high percentage of cubic phase zirconia, has less strength and fracture toughness than materials containing mainly tetragonal phase zirconia ${ }^{10,35)}$. We found that Zpex Smile, which contained a large amount of cubic phase zirconia, had lower fracture toughness than the other zirconia samples. This may have been because stress-induced transformation ${ }^{39)}$, the reason that tetragonal phase zirconia is quite strong, does not take place in Zpex Smile, in which cubic phase zirconia predominates.

\section{CONCLUSIONS}

When $\mathrm{Tm}_{2} \mathrm{O}_{3}$ was added to yttria-stabilized zirconia, the resulting materials emitted blue fluorescence with a peak wavelength that was close to that of natural teeth when irradiated with UV light. Notably, the translucent dental zirconia that consisted primarily of the tetragonal phase exhibited its highest fluorescent intensity when $0.8 \mathrm{wt} \% \mathrm{Tm}_{2} \mathrm{O}_{3}$ was added to the material. This study suggested that if the addition of $\mathrm{Tm}_{2} \mathrm{O}_{3}$ to yttriastabilized zirconia is limited to the concentration range examined, the microstructure and fracture toughness of either form of zirconia are not affected. Therefore, this work gives a simple and effective method for making fluorescent dental zirconia.

\section{ACKOWLEDGMENTS}

This study was supported in part by a Grant-in Aid for Scientific Research (17K11745) from the Ministry of Education, Culture, Sports, Science and Technology in Japan.

\section{REFERENCES}

1) Guazzato M, Albarkry M, Ringer SP, Swain MV. Strength, fracture toughness and microstructure of a selection of allceramic materials. Part 2. Zirconia-based dental ceramics. Dent Mater 2001; 20: 449-456.

2) Manicone PF, Rossi Iommetti P, Raffaelli L. An overview of zirconia ceramics: basic properties and clinical applications. J Dent 2007; 35: 819-826.

3) Denry I, Kelly JR. State of the art of zirconia for dental applications. Dent Mater 2008; 24: 299-307.

4) Koutayas SO, Vagkopoulou T, Pelekanos S, Koidis P, Strub JR. Zirconia in dentistry: part 2. Evidence-based clinical breakthrough. Eur J Esthet Dent 2009; 4: 348-380.

5) Sailer I, Gottnerb J, Kanelb S, Hammerle CH. Randomized clinical trial of zirconia-ceramic and metal-ceramic posterior fixed dental prostheses: a 3-year follow-up. Int J Prosthodont 2009; 22: 553-560.

6) Sax C, Hammerle CH, Sailer I. 10-year clinical outcomes of fixed dental prosthesis with zirconia frameworks. Int $\mathrm{J}$ Comput Dent 2011; 14: 183-202.

7) Miyazaki T, Nakamura T, Matsumura H, Ban S, Kobayashi T. Current status of zirconia restoration. J Prosthodont Res 2013; 57: 236-261.

8) Rinke S, Fischer C. Range of indications for translucent zirconia modifications: clinical and technical aspects. Quintessence Int 2013; 44: 557-566.

9) Sulaiman TA, Abdulmajeed AA, Donovan TE, Cooper LF, Walter R. Fracture rate of monolithic zirconia restorations up to 5 years: A dental laboratory survey. J Prosthet Dent 2016; 116: 436-439.

10) Carrabba M, Keeling AJ, Aziz A, Vichi A, Fabian Fonzar R, Wood D, Ferrari M. Translucent zirconia in the ceramic scenario for monolithic restorations: A flexural strength and translucency comparison test. J Dent 2017; 60: 70-76.

11) Spitzer D, Bosch JJ. The total luminescence of bovine and human dental enamel. Calcif Tissue Res 1976; 20: 201-208.

12) Kvaal S, Solheim T. Fluorescence from dentin and cementum in human mandibular second premolars and its relation to age. Scand J Dent Res 1989; 97: 131-138.

13) Alfrano RR, Yao SS. Human teeth with and without dental caries studied by visible luminescent spectroscopy. J Dent Res 1981; 60: 120-122.

14) Monsenego G, Burdairon G, Clerjaud B. Fluorescence of dental porcelain. J Prosthet Dent 1993; 69: 106-113.

15) Lee YK, Lu H, Powers JM. Fluorescence of layered resin composites. J Esthet Restor Dent 2005; 17: 93-100.

16) Nakamura T, Okamura S, Nakano Y, Wakabayashi K, Nishida H, Sekino T, Yatani H. Comparison of fluorescence of zirconia with glass ceramics for CAD-CAM restoration. J Jpn Acad Digit Dent 2017; 7: 24-28.

17) Lucas J, Lucas P. Chapter 15 - Introduction to rare earth luminescent materials. Rare Earths 2015: 51-280.

18) Standard: JSA - JIS R 1607. Testing methods for fracture toughness of fine ceramics at room temperature. Japanese Standards Association 2015.

19) Harada K, Shinya A. Evaluation of fracture toughness using SEVNB and IF method for zirconia (Y-TZP). Ann Jpn Prosthodont Soc 2013; 5: 165-173.

20) Peplinski DR, Wozniak WT, Moser JB. Spectral studies of new luminophors for dental porcelain. J Dent Res 1980; 59: 
1501-1506.

21) Wozniak WT, Moore BK. Luminescence spectra of dental porcelains. J Prosthet Dent 1978; 57: 971-974.

22) Ecker GA, Moser JB, Wozniak WT, Brinsden GI. Effect of repeated firing on fluorescence of porcelain-fused-to-metal porcelains. J Prosthet Dent 1985; 54: 207-214.

23) Bodisova K, Klement R, Galusek D, Pouchly V, Drdlik D, Maca K. Luminescent rare-earth-doped transparent alumina ceramics. J Eur Ceram Soc 2016; 36: 2975-2980.

24) Zhang H, Fu X, Niu S, Xin Q. Blue emission of $\mathrm{ZrO} 2$ : Tm nanocrystals with different crystal structure under UV excitation. J Non Cryst Solids 2008; 354: 1559-1563.

25) Seeta Rama Raju G, Pavita E, Yu JS. Cross-relaxation induced tunable emissions from the $\mathrm{Tm}^{3+} / \mathrm{Er}^{3+} / \mathrm{Eu}^{3+}$ ions activated $\mathrm{BaGd}_{2} \mathrm{O}_{4}$ nanoneedles. Dalton Trans 2014; 43: 9766-9776.

26) Ryabochkina PA, Borik MA, Kulebyakin AV, Lomoneva EE, Malov AV, Somov NV, Ushakov SN, Chabshkin AN, Chuprunov EV. Structure and spectral-luminescence properties of yttrium-stabilized zirconia crystals activated with $\mathrm{Tm}^{3+}$ ions. Opt Spectrosc 2012; 112: 594-600.

27) Matsumoto H, Kitamura S, Araki T. Autofluorescence in human dentine in relation to age, tooth type and temperature measured by nanosecond time-solved fluorescence microscopy. Arch Oral Biol 1999; 44: 309-318.

28) Wardle B. Lanthanide luminescence. Principles and applications of photochemistry, New York, Wiley 2009: 7475 .

29) Buenzil JC, Piguet C. Taking advent of luminescent lanthanide ions. Chem Soc Rev 2005; 34: 1048-1077.

30) Bonar JR, Vermelho MVD, McLaughlin AJ, Marques PVS, Aitchison JS, Martins-Filho JF, Bezerra-Jr AG, Gomes ASL, de Araujo CB. Blue light emission in thulium doped silica-on- silicon waveguides. Optics Comm 1997; 141: 137-140.

31) Dai S, Yu C, Zhou G, Zhang J, Wang G, Hu L. Concentration quenching in erbium-doped tellurite glasses. J Lumin 2006; 117: 39-45.

32) Pugliese D, Boetti NG, Lousteau J, Ceci-Ginistrelli E, Bertone E, Geobaldo F, Milanese D. Concentration quenching in an Er-doped phosphate glass for compact optical lasers and amplifiers. J Alloys Compd 2016; 657: 678-683.

33) Wang R, Liu J, Zhang Z. Luminescence and energy transfer progress in $\mathrm{Bi}-\mathrm{Yb}$ co-doped germanate glass. J Alloys Compd 2016; 688: 332-336.

34) Matsuzaki F, Sekine H, Honma S, Takanashi T, Furuya K, Yajima Y, Yoshinari M. Translucency and flexural strength of monolithic translucent zirconia and porcelain-layered zirconia. Dent Mater J 2015; 34: 910-917.

35) Zhang F, Inokoshi M, Batuk M, Hadermann J, Naert I, Van Meerbeek B, Vleugels J. Strength, toughness and aging stability of highly-translucent Y-TZP ceramics for dental restorations. Dent Mater 2016; 32: e327-e337.

36) Hallmann L, Ulmer P, Reusser E, Louvel M, Hämmerle CHF. Effect of dopants and sintering temperature on microstructure and low temperature degradation of dental Y-TZP-zirconia. J Eur Ceram Soc 2012; 32: 4091-4104.

37) Ban S. Technical factors affecting the properties of dental zirconia. Proceedings of the International Dental Materials Congress 2011: 69-79.

38) Peuchert U, Okano Y, Menke Y, Reichel S, Ikusue A. Transparent cubic-ZrO2 ceramics for application as optical lenses. J Eur Cer Soc 2009; 29: 283-291.

39) Budiansky, Truskinovsky BL. On the mechanics of stressinduced phase transformation in zirconia. J Mech Phys Solids 1993; 41: 1445-1459. 